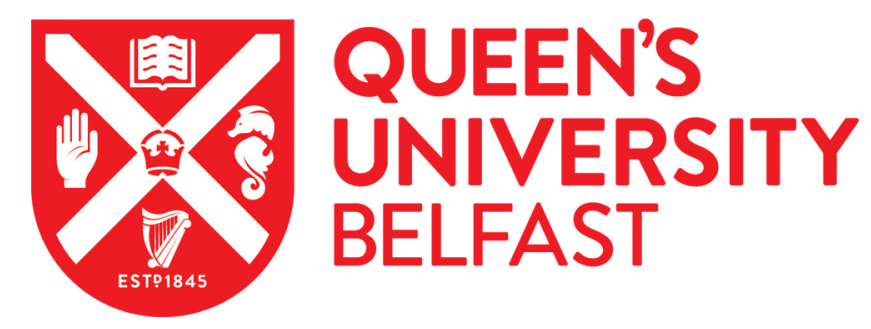

\title{
Full Battery Pack Modelling: An Electrical Sub-Model Using an EECM for HEV Applications
}

Rolt, R., Douglas, R., Nockemann, P., \& Best, R. (2019). Full Battery Pack Modelling: An Electrical Sub-Model Using an EECM for HEV Applications. SAE Technical Papers, [2019-01-1203]. https://doi.org/10.4271/2019-011203

\section{Published in:}

SAE Technical Papers

\section{Document Version:}

Peer reviewed version

Queen's University Belfast - Research Portal:

Link to publication record in Queen's University Belfast Research Portal

Publisher rights

(c) SAE International. All Rights Reserved.

This work is made available online in accordance with the publisher's policies. Please refer to any applicable terms of use of the publisher.

\section{General rights}

Copyright for the publications made accessible via the Queen's University Belfast Research Portal is retained by the author(s) and / or other copyright owners and it is a condition of accessing these publications that users recognise and abide by the legal requirements associated with these rights.

Take down policy

The Research Portal is Queen's institutional repository that provides access to Queen's research output. Every effort has been made to ensure that content in the Research Portal does not infringe any person's rights, or applicable UK laws. If you discover content in the Research Portal that you believe breaches copyright or violates any law, please contact openaccess@qub.ac.uk. 


\section{Full Battery Pack Modelling: An Electrical Sub-Model Using an EECM for HEV Applications}

\begin{abstract}
With a transition towards electric vehicles for the transport sector, there will be greater reliance put upon battery packs; therefore, battery pack modelling becomes crucial during the design of the vehicle. Accurate battery pack modelling allows for: the simulation of the pack and vehicle, more informed decisions made during the design process, reduced testing costs, and implementation of superior control systems. To create the battery cell model using MATLAB/Simulink, an electrical equivalent circuit model was selected due to its balance between accuracy and complexity. The model can predict the state of charge and terminal voltage from a current input. A battery string model was then developed that considered the cell-to-cell variability due to manufacturing defects. Finally, a full battery pack model was created, capable of modelling the different currents that each string experiences due to the varied internal resistance. The model was then validated with real-life data from the "Hill Route" section of the First Group Millbrook Fuel Economy Test Version 5.0 drive cycle of a mild hybrid electric bus. Results showed a strong correlation with the measured data and both the state of charge and terminal voltage simulations of the model. For the string model, results showed that there was a slight variance in the state of charge between cells in a string with varied capacities. However, terminal voltages between cells did not vary significantly with variances in internal resistance. Future work includes the creation of a thermal sub-model and an ageing submodel, which considers whether the location of a cell within a pack has a correlation with its degradation. These sub-models will then be integrated and used as a full battery pack model.
\end{abstract}

\section{Introduction}

With the increasing concern of global warming, there has been great emphasis put upon initiatives and legislation created by governments and organizations to reduce greenhouse gas (GHG) emissions from sectors such as energy and transport. As of 2016 in the United Kingdom (UK), the transport sector has overtaken the energy sector to be the largest emitter of GHGs. In addition to this, the energy sector has reduced its GHG emissions by more than half since 1990, whereas transport has had no significant change [1]. Due to the increasing legislation passed by the UK government, there will likely be a gradual transition towards electric vehicles (EVs), with hybrid EVs (HEVs) acting as an intermediate step. This transition will reduce the overall tank-to-wheel (TTW) emissions from the transport sector.

With a transition towards EVs, greater reliance will be placed upon battery packs and therefore, battery pack modelling becomes crucial during the design of the vehicle. Accurate battery pack modelling allows for: the simulation of the pack and vehicle, more informed decisions made during the design process, reduced testing costs, and implementation of superior control systems.

\section{Background \\ Cell Modelling}

Much research has been undertaken at a battery cell level, with many different models being used that include: an electrochemical model, an electrical equivalent circuit model (EECM), and black box methods, such as a neural network model. An electrochemical model is a forward-facing model that builds upon fundamental equations derived from first principles, such as the electrochemical and physical partial differential equations that govern the flow of ions through a lithiumion (Li-ion) cell. For example, Zheng et al. used a one-dimensional (1D) spatial model, where the spatiotemporal dynamics such as Li-ion concentration, electric potential, and intercalation kinetics can be modelled [2]. This results in a model capable of high accuracy but at the expense of high complexity and high computational costs. According to Jokar et al., the two most popular electrochemical models are the pseudo-two-dimensional (P2D) model and the single particle model (SPM) [3], as shown in Figure 1 and Figure 2 respectively. The P2D model uses porous electrode theory and concentrated solution theory, where the electrodes are modelled containing identical spherical particles, and it assumes that diffusion occurs primarily in the radial direction [4]. Pramanik and Anwa used an SPM, which streamlines the full physics-based model by ignoring the properties of the electrolyte and modelling the electrodes as two spherical particles [5]. The SPM is, therefore, less complex but is unsuitable for high discharge rates, where the electrolyte properties cannot be ignored [3].

A common example of a black-box battery cell model is the artificial neural network (ANN). An ANN imitates human brain neuron systems, where inputs are passed through a network of previously trained weights to simulate an output. The main advantage of using an ANN is the ability to estimate an output without prior knowledge of the system. This means that it can be applied to a nonlinear system and estimate an accurate output, depending on the quality of the training data [6]. An ANN contains three layers: an input layer, a hidden layer, and an output layer (see Figure 3). The connections between layers are weighted, where they are then summed and passed through activation functions at the hidden layer nodes. These weights are trained to give the optimal output, which is optimised using target training values. Andre et al. applied a neural network model to a battery cell by calculating the state of charge (SOC) separately and using it, in addition to current and temperature, as inputs for the estimation of the terminal voltage [7]. This was developed using multiple structured neural networks, where internal weights have a physical meaning assigned, contrary to conventional ANNs. Dang et al. similarly applied an ANN to estimate the terminal voltage, using previous time steps of both current and terminal voltage as inputs [8]. However, their methodology differs by combining a linear neural network, to initially estimate the terminal voltage and open-circuit voltage (OCV), with a back-propagating ANN to estimate SOC from this OCV. Black-box 
modelling has the advantages of being computationally faster and does not require prior knowledge of the inner behaviour of the system; however, it is not very robust between different cell chemistries or different boundary conditions, as retraining is then required.

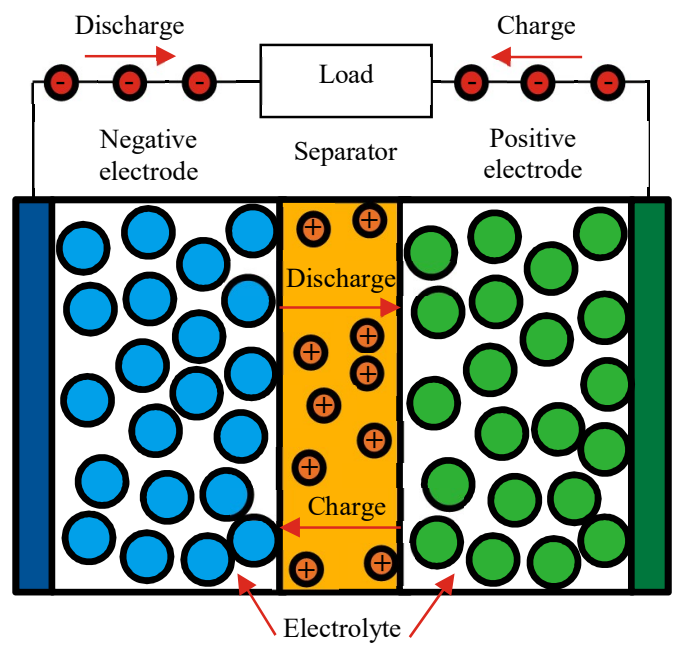

Figure 1. Electrochemical P2D model (adapted from [3])

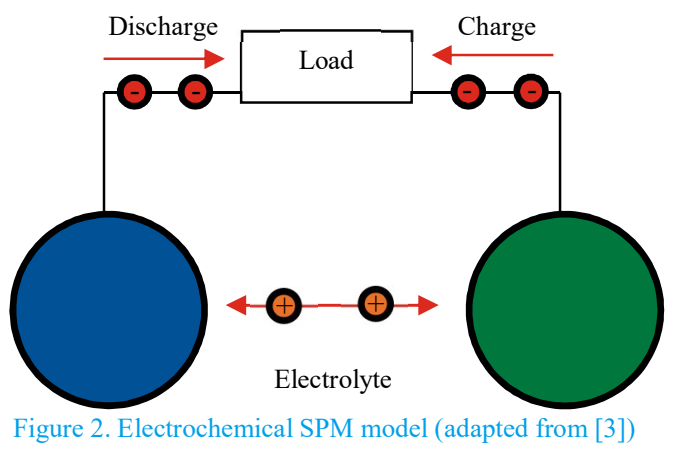

The most common cell modelling method is the EECM, which is a grey-box model. An EECM uses components in an electrical circuit to simulate different aspects of a battery cell's response when a load or power source is applied or removed. It is a grey-box model because the components represent real phenomena of the cell, but the parameters of these components are empirically determined. The Rint model is a very basic EECM, as it is linear in its voltage response; a schematic of the model is shown in Figure 4. It includes an ideal voltage source to represent the battery cell's OCV and a resistor in series to describe the internal ohmic losses due to contacts, electrodes and the battery electrolyte. This method, however, does not capture the dynamics during transient states and would be inappropriate for HEV applications, where the current can fluctuate dramatically.

A Thevenin's model, or first-order resistor-capacitor (RC) model, is an expansion of the Rint model but also includes an RC parallel branch to capture the dynamic behaviour of the battery (see Figure 5). The RC branch attempts to model the ion mass transfer and the chemical reactions at the electrode surface. According to Nikolian et al. (2014), whilst the first-order RC model considers ohmic and concentration polarisations, there is also an activation polarisation related specifically to the electrochemical reactions at the electrode surface that should be accounted for [9]. Nikolian et al. (2018) account for this activation polarisation by adding a second $\mathrm{RC}$ parallel branch to the Thevenin model to accurately capture the dynamics of the system [10]. Jackey et al. explain that adding more $\mathrm{RC}$ network branches improves the accuracy of the model but at the expense of greater complexity, which is shown in their model containing three RC branches [11]. In contrast, Nejad et al. argue that the use of two RC network branches is optimal, but if there are large hysteresis effects, then one RC network branch is preferred [12]. Hu et al. agree with this statement by adding that the complexity beyond two RC network branches is unhelpful and for lithium iron phosphate (LFP), which has a large hysteresis effect, a first-order RC model with one-state hysteresis is preferred [13].

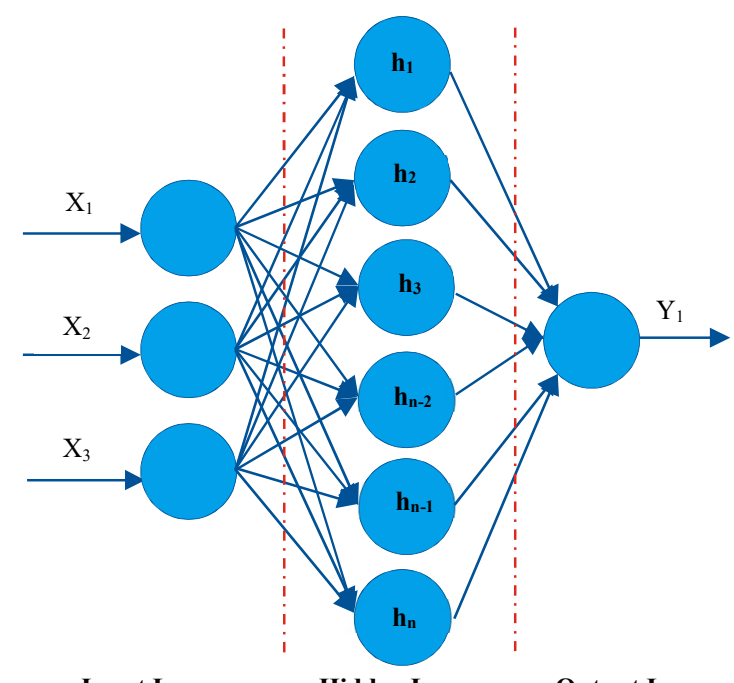

Figure 3. Neural Network

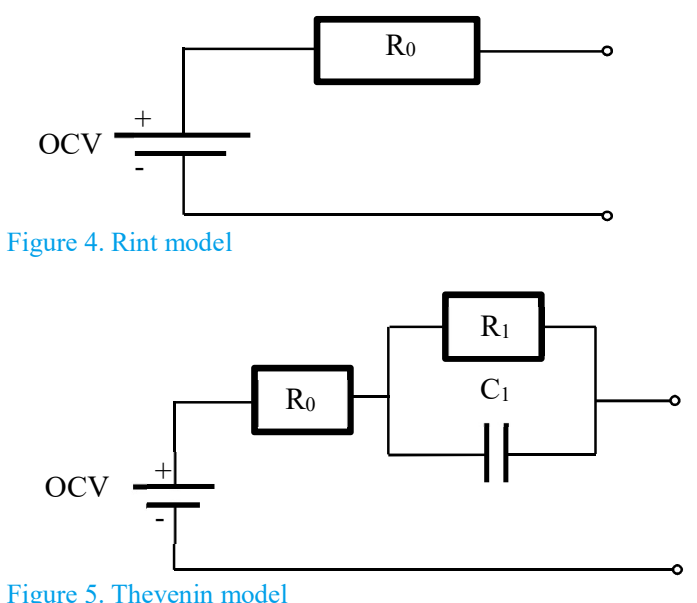

The hysteresis effect is a phenomenon, where the OCV exhibits different trajectories when converging to its equilibrium voltage, depending on its previous charging or discharging states. The effect of voltage hysteresis can be seen in Figure 6, where the lower trajectory of the "eye" converges towards the discharging boundary curve. It then changes direction before gradually converging towards the charging boundary curve when the current direction switches. This phenomenon means that a battery's OCV and SOC do not share a one-to-one relationship during partial cycles. The boundary curves are collectively called the major loop and they represent the OCV during full charging and full discharging. Cells with two-phase active materials, such as lithium iron phosphate $\left(\mathrm{LiFePO}_{4}\right.$ or LFP), lithium titanate $\left(\mathrm{Li}_{4} \mathrm{Ti}_{5} \mathrm{O}_{12}\right.$ or LTO), and lithiated graphite $\left(\mathrm{LiC}_{6}\right)$, show a pronounced hysteresis effect. Two-phase transition lithium insertion is where lithium insertion is accompanied by a first-order phase transformation from a lithium lean phase to a lithium rich phase [14]. Mechanical stresses at these phase barriers lead to voltage drops inside individual particles and this, in conjunction with differing lithium insertion rates into the 
electrode from variations in particle sizes, causes the hysteresis effect [15].

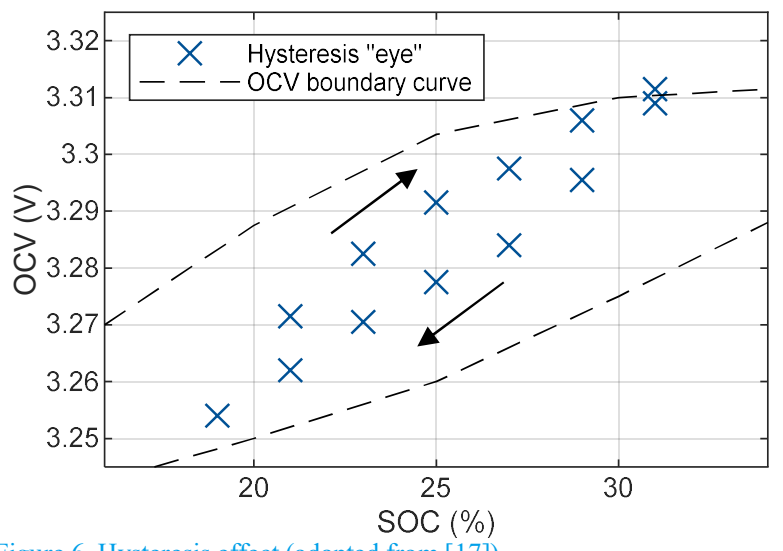

Figure 6. Hysteresis effect (adapted from [17])

A simple method of modelling hysteresis is to create separate look-up tables for OCV-SOC during both charge and discharge [16]; however, this will not fully capture the convergence of the voltage towards the major loop. Roscher et al. used both a recovery factor and a hysteresis factor in their calculation of the OCV [17]. The recovery factor was used to model the relaxation effect, which is the time-dependent convergence of the $\mathrm{OCV}$ to an equilibrium voltage. This equilibrium voltage is less than or greater than the true OCV, depending on whether it is following a discharge or charge respectively. The hysteresis factor determined whether the OCV was equal to the charging portion of the major loop, the discharging portion of the major loop, or somewhere in between; this factor has a dependence on current and time. A zerostate hysteresis model simply uses a hysteresis voltage that is half the difference between the two curves of the major loop and adds or subtracts this from the OCV depending on the direction of the current. Although this model does partially capture the hysteresis phenomenon, it instantaneously changes from one curve to the other as soon as the current changes direction, which is not representative of what occurs. The single-state hysteresis model takes into account the transition between curves by considering the rate of change of hysteresis voltage with respect to SOC [18].

\section{Pack Modelling}

When scaling up to a string of cells, one of the main issues is cell SOC imbalance. This can occur from either manufacturing defects or from the ageing mechanisms mentioned previously and can severely limit the capacity of the string if the imbalance is prominent. When the string is being discharged, the capacity of the string will be equal to the cell with the lowest remaining charge. Similarly, when the string is being charged, the string's charge capacity will be limited by the cell with the lowest remaining charge capacity; otherwise, this will cause overcharging of that cell and therefore increased degradation. These limitations of cells in series were discussed by Zhong et al.; however, they assumed that for cells in parallel, the cells would eventually balance each other out and whilst this is technically true, they do not take into account the degradation that occurs during this process [19]. For cells arranged in parallel, a concern is uneven current distribution due to differences in internal resistance. Cells with lower internal resistances will experience a higher current and will, therefore, reach a higher SOC during charging than those with higher internal resistance. Once these cells have reached a sufficiently high SOC and their internal resistance has increased, the current will then decrease through these cells. The current will then increase through the cells with the now lower resistance and will eventually cause a self- balancing effect as mentioned previously. This was identified by Gogoana et al., stating that even though the mean current between strings could be fixed, the maximum current that a string with lower resistance experiences could lead to accelerated degradation [20]. The results of the experiments performed by Gogoana et al. suggested that a $20 \%$ difference between the internal resistances of two cells in parallel could lead to an approximate $40 \%$ reduction in cycle life of the pack when compared to two cells with very similar internal resistance. Gong et al. showed similar results, where cells in parallel that had been degraded differently caused large differences in current and resulted in accelerated degradation [21]. These variations in current can also cause uneven heat generation across the pack, so this should be considered when modelling a full battery pack.

To model the effect of parallel cells, Bruen and Marco used an EECM for cells and joined them together in parallel, with resistors to represent interconnections. The current in each mesh was calculated using Kirchhoff's laws. They then expanded on the self-balancing nature of SOC between parallel cells mentioned previously by suggesting that the $\mathrm{SOH}$ of these cells would also converge. This convergence is due to cells with lower SOHs having slower degradation because of increased resistance and therefore lower currents passing through them [22].

When compared to cell modelling, there is a lack of literature relating to full battery pack modelling. Included in this literature, there are papers that model battery packs as large cells [23], which is incorrect as this method will not take into account the variability between cells or show a true reflection of the temperature distribution across the pack. To show cell-to-cell variations, Yurkovic and Guezennec used a randomly generated uniform distribution of numbers within specified limits to model the deviation of parameters from their nominal values [24]. Kenney et al. used a similar approach but used a normal distribution for the variations of parameters to model the variations due to manufacturing [25]; Dubarry et al. found these deviations to be $\pm 1.9 \%$ for cell capacity [26]. To the author's best knowledge, there are few battery pack models that simultaneously consider electrical modelling, thermal modelling, and ageing modelling in literature, with the exception of Cordoba-Arenas et al. [27]. Their model considers cell-to-cell variations, temperature generation and propagation, and then these sub-models feed into the ageing model.

After reviewing the relevant literature, the objective of this paper is to create an electric model of a battery pack for HEV applications that considers cell-to-cell variations and shows the effects of these variations when placed in series and in parallel. The model should be capable of SOC estimation and terminal voltage simulation at cell and pack level and will be validated with real-life mild HEV bus data.

\section{Methodology}

For the battery cell and pack, MATLAB/Simulink was used to create an integrated model with easily changeable parameters for robustness between different chemistries. The initial battery chemistry selected was LTO to match with industrial standards.

\section{Cell Model}

For SOC estimation, a simple coulomb counting method has been used as an initial estimation due to its low complexity and reasonable accuracy, which can be seen in Eq. (1):

$$
\operatorname{SOC}[k+1]=\operatorname{SOC}[k]-\frac{\eta i_{c e l l}[k] \Delta t}{C}
$$


Where:

$\eta=$ coulombic efficiency

$i_{\text {cell }}=$ cell current at sample $k$

$\Delta t=$ time step

$C=$ cell capacity

The available battery pack data were obtained via a controller area network (CAN) bus implemented on a mild HEV bus operating on the "Hill Route" portion of the First Group Millbrook Fuel Economy Trial Version 5.0 (FMFETv5) drive cycle. Due to the nature of the communication system, even though the parameters were all measured at $10 \mathrm{~Hz}$, the timestamps do not match exactly when comparing parameters; therefore, resampling of the data was required through interpolation to give a constant time step.

To model the battery cell, the EECM method was selected as this is a reasonable balance between accuracy and complexity. The proposed model is shown in Figure 7, where each component of the circuit represents a different aspect of the battery cell's behaviour when a load is applied or removed. The ideal voltage source is the OCV and the cell terminal voltage, $v_{\text {cell }}$ is determined by calculating the voltage across other components and subtracting or adding this to the OCV, depending on whether the circuit is being charged or discharged through a load. The series resistor $R_{0}$, represents the ohmic voltage drop when a load is applied across the battery; this is due to resistance in the electrolyte and electrodes. The RC network consisting of a resistor and capacitor, $R_{1}$ and $C_{1}$ respectively, represents the dynamic voltage response, which models the relaxation effect of the cell. This effect is due to the nonlinear process of ion mass transfer through the electrodes and reactions that occur at the electrodes. These resistances and capacitance were calculated from the drive cycle data and then optimised for the best suited parameters. The OCV is a function of SOC, where there is a bijective mapping between the two when hysteresis is ignored and only the major loop is considered; therefore, a simple look-up table was used and the mean OCV between charging and discharging for a given SOC was calculated.

To calculate the voltage across the RC network, the current in the branch was initially calculated. The sum of the currents passing through both the resistor $i_{R 1}$, and the capacitor $i_{C 1}$, at time $t$ will be equal to the overall cell current; therefore, Eq. (2) can be generated:

$$
i_{\text {cell }}(t)=i_{R 1}(t)+i_{C 1}(t)
$$

The current through the capacitor can be rewritten using Eq. (3) and Eq. (4), where $v_{C 1}$ and $\dot{v}_{C 1}$ are the voltage and rate of change of voltage across the capacitor respectively:

$$
i_{C 1}(t)=C_{1} \dot{v}_{C 1}(t)
$$

$$
v_{C 1}(t)=R_{1} i_{R 1}(t)
$$

Thus, (2) can be rewritten as (5):

$$
i_{\text {cell }}(t)=i_{R 1}(t)+R_{1} C_{1} \frac{\mathrm{d} i_{R 1}(t)}{\mathrm{d} t}
$$

Rearranging Eq. (5) to make the rate in change of current through the resistor the subject gives Eq. (6):

$$
\frac{\mathrm{d} i_{R 1}(t)}{\mathrm{d} t}=\frac{1}{R_{1} C_{1}} i_{\text {cell }}(t)-\frac{1}{R_{1} C_{1}} i_{R 1}(t)
$$

Through further derivation, the current through the resistor can be given by Eq. (7):

$$
i_{R 1}[k+1]=i_{R 1}[k] \cdot e^{\frac{-\Delta t}{R_{1} C_{1}}}+\left(1-e^{\frac{-\Delta t}{R_{1} C_{1}}}\right) \cdot i_{c e l l}[k]
$$

To calculate the terminal voltage of the cell, the voltage drop across each component in the circuit is summed and either subtracted or added to the OCV, depending on whether the cell is being charged or discharged. To model the hysteresis voltage $(h)$, Eq. (8) is used, where $\gamma$ is the hysteresis factor and $M$ is the maximum hysteresis [18]

$$
h[k+1]=e^{\frac{\eta i_{\text {cell }}[k] \gamma \Delta t}{C}} \cdot h[k]+\left(1-e^{\frac{\eta i_{\text {cell }}[k] \gamma \Delta t}{C}}\right) \cdot M
$$

With the hysteresis voltage calculated, the terminal voltage can then be determined using Eq. (9):

$$
v_{\text {cell }}[k]=O C V(S O C)+h[k]-R_{1} i_{R 1}[k]-R_{0} i_{c e l l}[k]
$$

\section{Pack Model}

When scaling the model up to a string of cells, a normal distribution function was applied to both the cell capacities and their internal series resistance. This distribution gives an approximation of the variation in cells through manufacturing defects. The capacity and internal series resistance distributions across the pack are shown in Figure 8 and Figure 9 respectively.

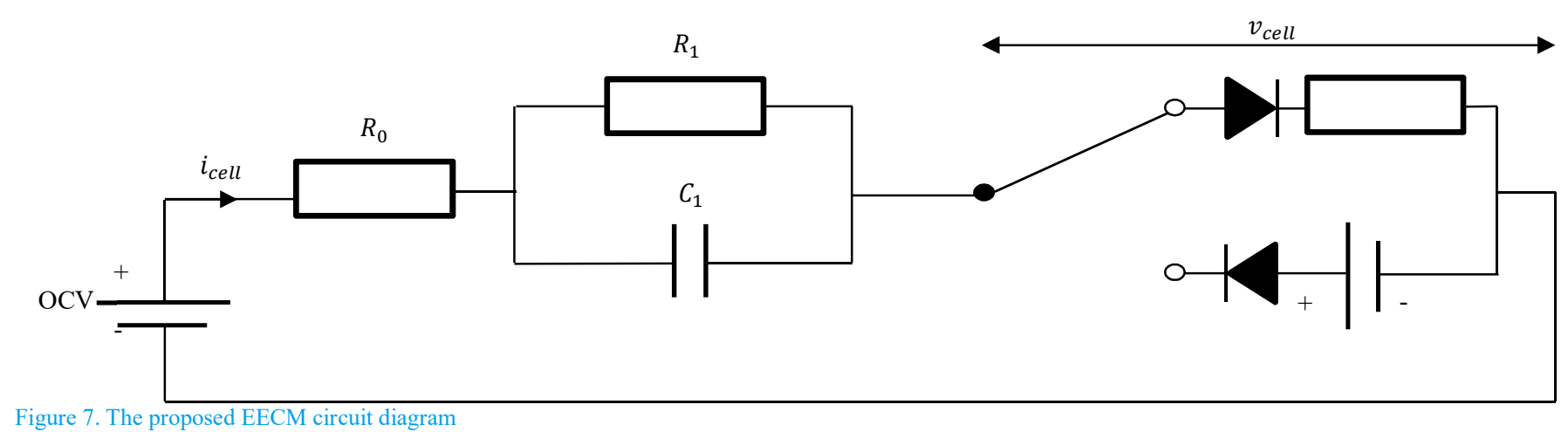

Figure 7. The proposed EECM circuit diagram 


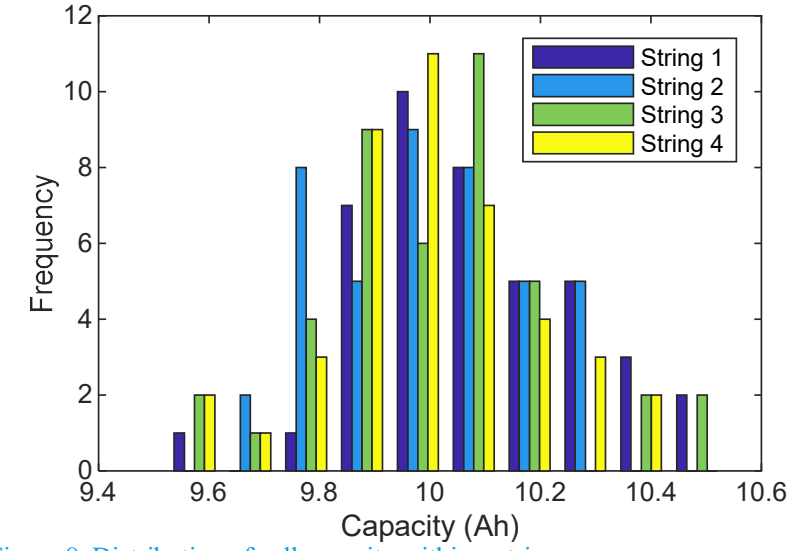

Figure 8. Distribution of cell capacity within a string

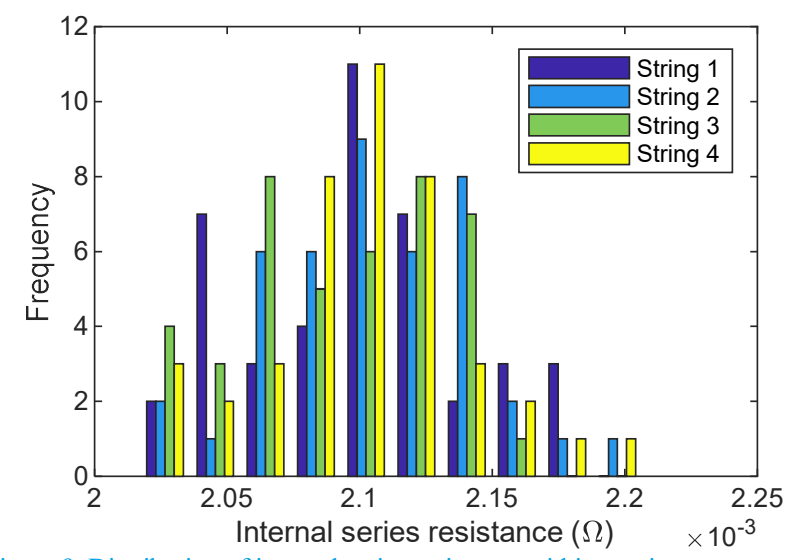

Figure 9. Distribution of internal series resistance within a string

To model the parallel strings, and therefore the full battery pack, the current variation between strings was considered. As strings will have different resistances due to the manufacturing defects of constituent cells, they will consequently experience different currents passing through them. The configuration of a general battery pack is shown in Figure 10, where each cell in a string has its own internal series resistance. The resistance of each string $\left(R_{i}\right)$ is simply the sum of each constituent cell's resistance $\left(R_{i j}\right)$, as shown in Eq. (10), where $m$ is the number of strings in the pack and $n$ is the number of cells in series:

$$
R_{i}=R_{i 1}+R_{i 2}+\cdots+R_{\text {in }}
$$

To find the overall pack resistance $\left(R_{T}\right)$, Eq. (11) is used for resistors in parallel:

$$
\frac{1}{R_{T}}=\frac{1}{R_{1}}+\frac{1}{R_{2}}+\cdots+\frac{1}{R_{m}}
$$

Ohm's law can then be used to find the string current $\left(i_{i}\right)$ as a function of: string resistance, pack resistance, and pack current $(I)$ through substitution of Eq. (12) into Eq. (13), which eliminates the pack voltage $\left(V_{\text {pack }}\right)$ :

$$
\begin{gathered}
V_{\text {pack }}=I R_{T} \\
i_{i}=\frac{V_{\text {pack }}}{R_{i}}=I \frac{R_{T}}{R_{i}}
\end{gathered}
$$

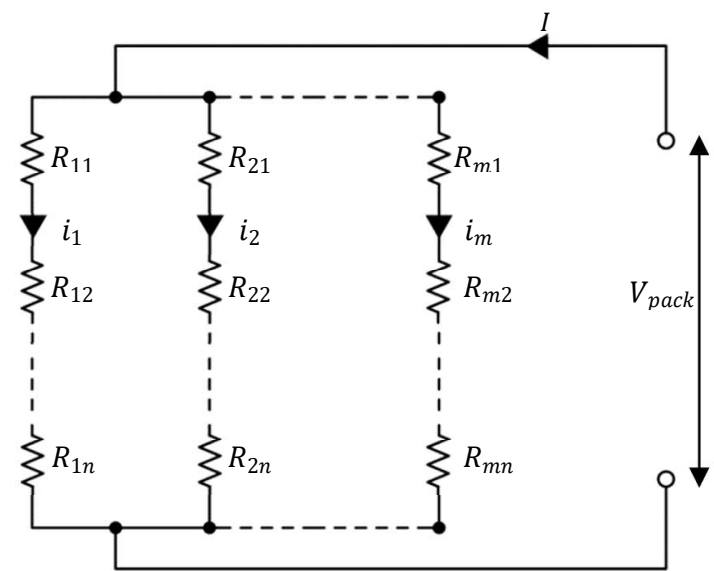

Figure 10. Battery pack configuration

\section{Results and Discussion}

A current input was applied to the model (as shown in Figure 11), which was obtained from the CAN bus onboard of a mild HEV bus performing on the "Hill Route" portion of the FMFETv5 drive cycle, where discharge current is the positive convention. The current has been normalized in terms of C-rate, which is the ratio of the current to the cell capacity. On charge, the current input reaches peaks of approximately $10 \mathrm{C}$ and on discharge, it reaches peaks of over $15 \mathrm{C}$.

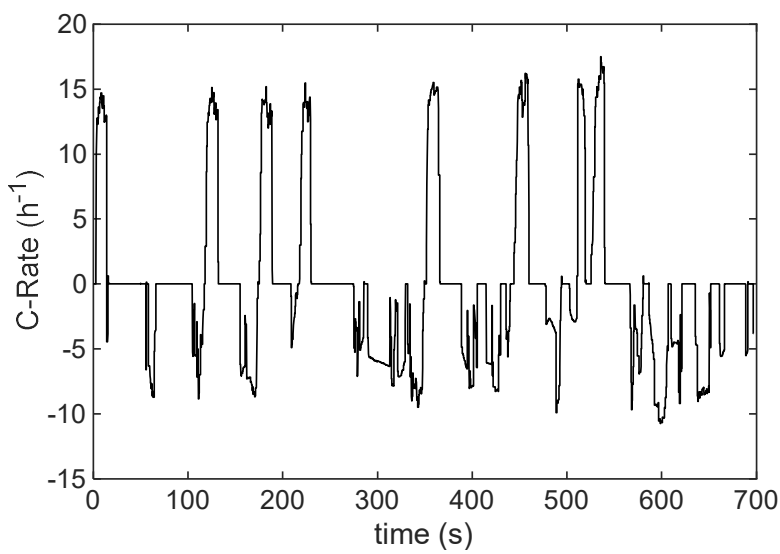

Figure 11. Cell current input

The SOC data was also obtained from the onboard CAN bus and then plotted with the cell SOC predicted by the model in Figure 12; the simulated SOC shows a very strong correlation with the measured SOC. Any discrepancies between the model's SOC prediction and the measured SOC can be explained by the limited precision of the measurement tool, as it appears to have an increment of only $0.5 \%$.

Similarly, the cell terminal voltage simulated by the model shows a strong correlation with the CAN bus terminal voltage (see Figure 13). The differences between the predicted voltage and the measured voltage, especially at the peaks, could possibly be due to measurement noise of the voltmeter, which would be amplified with a more dynamic dataset. These divergences could also suggest that further optimization of the EECM parameters is required. The error distribution for the terminal voltage can also be seen in Figure 14. The error distribution is centred on a mean of $-0.406 \%$, with a standard deviation of $1.28 \%$. 


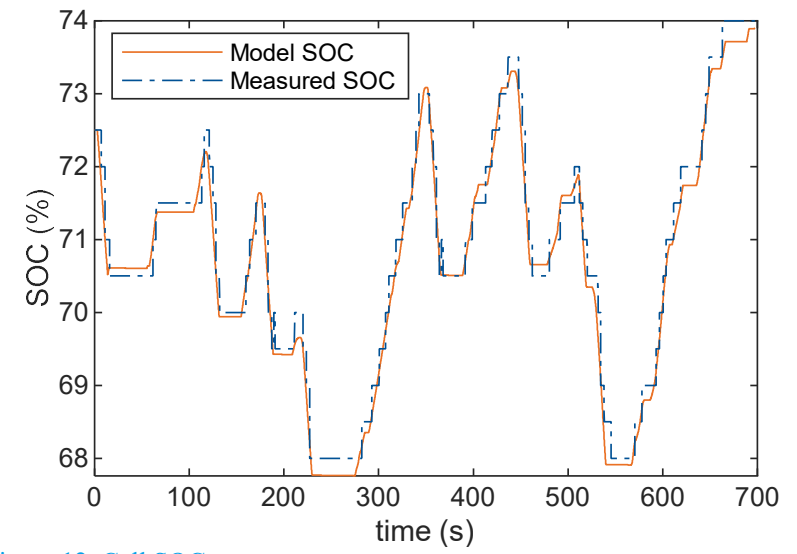

Figure 12. Cell SOC

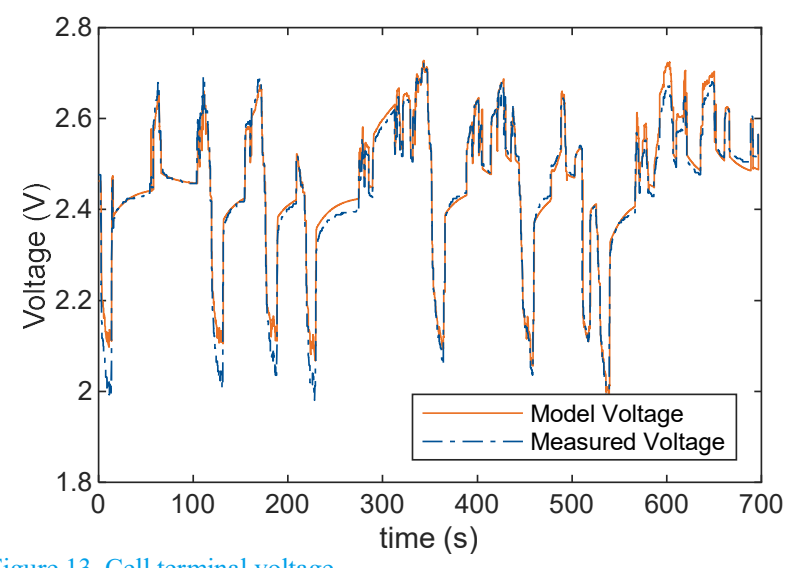

Figure 13. Cell terminal voltage

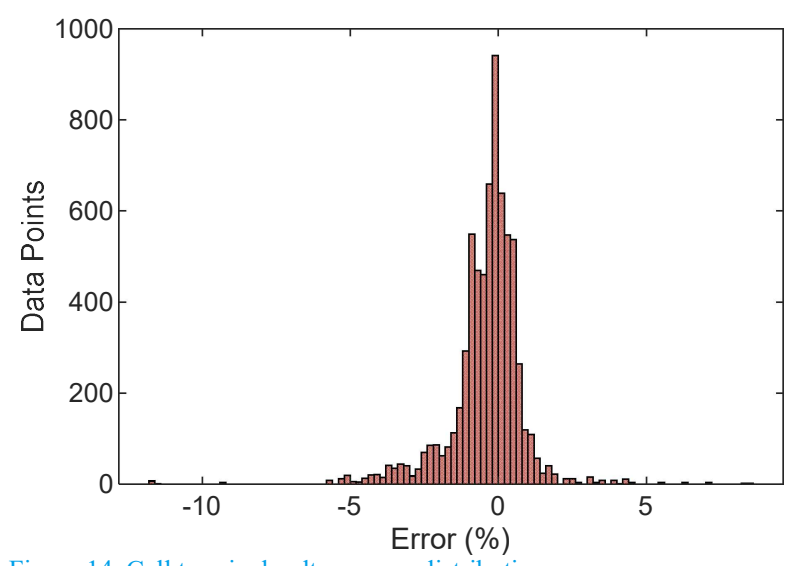

Figure 14. Cell terminal voltage error distribution

For the string model of 42 cells in series, the variation in capacity caused a slight difference in SOC between cells, as shown in Figure 15. A magnified view of the SOC variation between cells is shown in Figure 16, where there is almost $0.4 \%$ between the highest and lowest charged cells in the string. Over a full drive cycle, this could become more prominent, especially when capacity degradation is introduced into the model. On the contrary, the distribution of internal series resistance did not appear to have a great effect on the terminal voltages of each cell, as shown in Figure 17 and the close-up in Figure 18. The difference between the highest and lowest cell terminal voltage in the string is only approximately $0.02 \mathrm{~V}$. These results imply that variations in capacity between cells in a string have a greater effect on the string model than variations in internal series resistance.

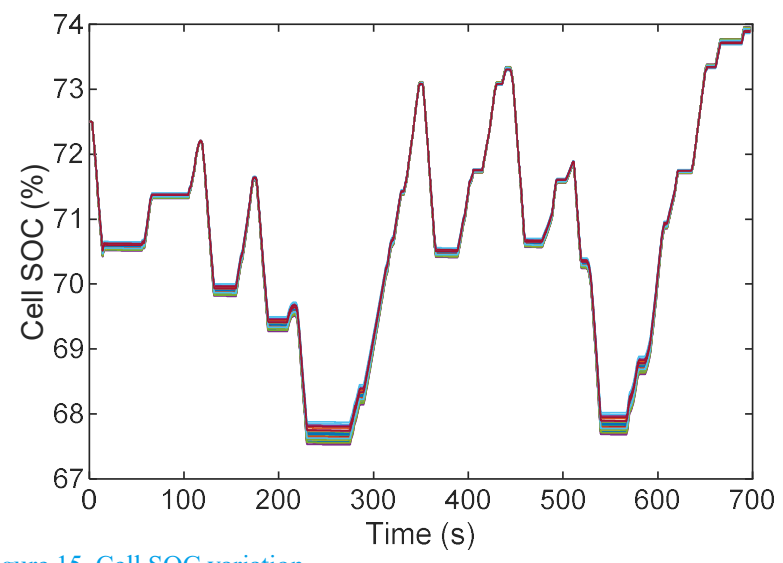

Figure 15. Cell SOC variation

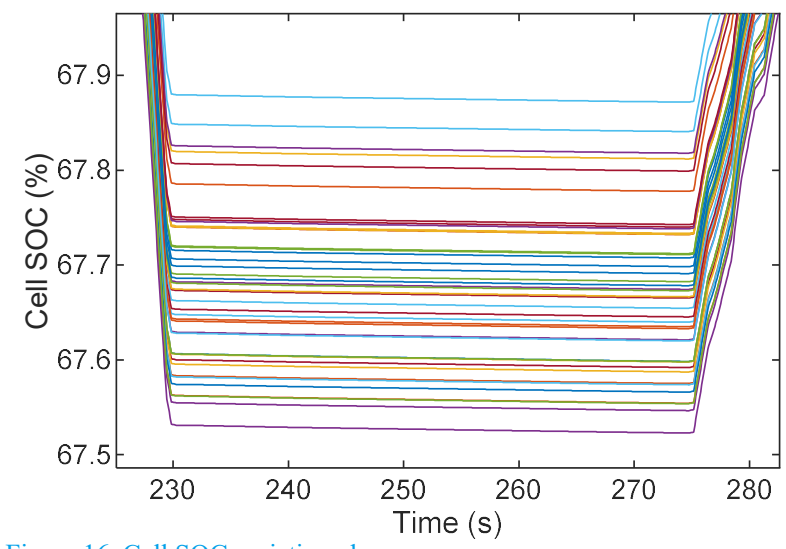

Figure 16. Cell SOC variation close-up

It should also be noted that when the voltages of the cells in series are summed to give the total string voltage, the result shows a similar response to the individual cell terminal voltage, as expected (see Figure 19). This shows that using a large cell model to replicate a string or pack could still have an accurate terminal voltage prediction, but it would not show the variance in SOC and terminal voltage amongst cells in the pack, which could cause unexpected failures.

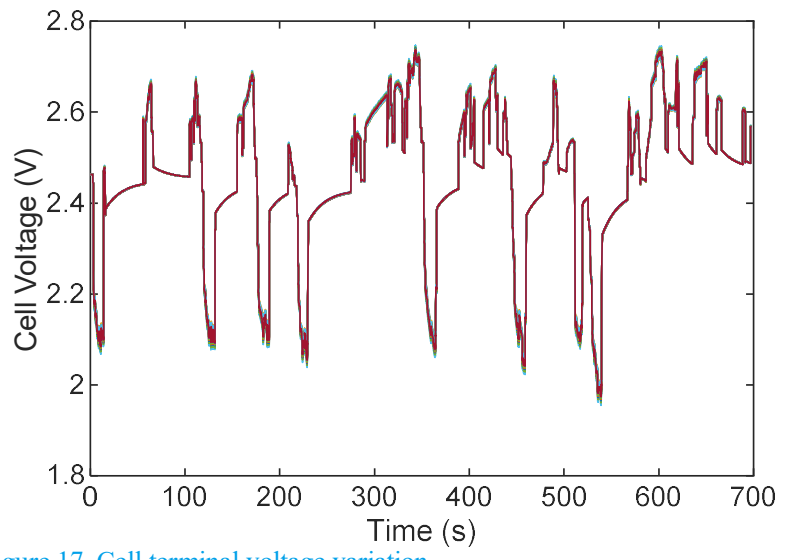

Figure 17. Cell terminal voltage variation 


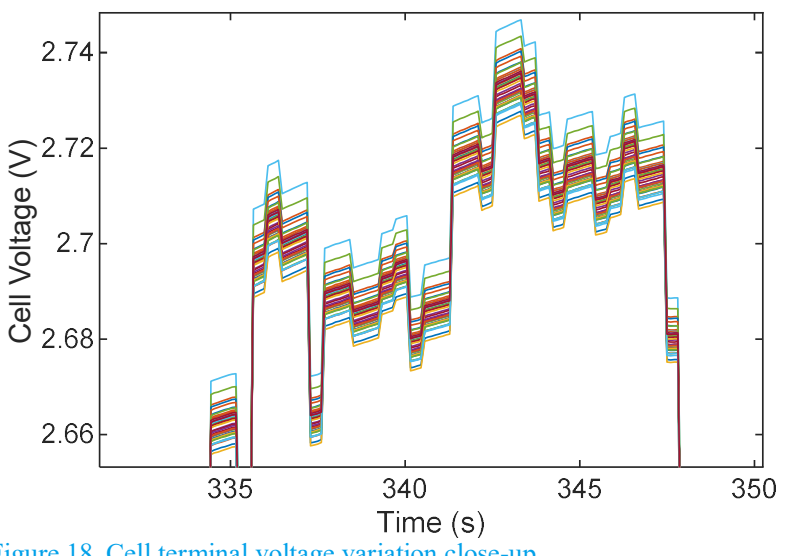

Figure 18. Cell terminal voltage variation close-up

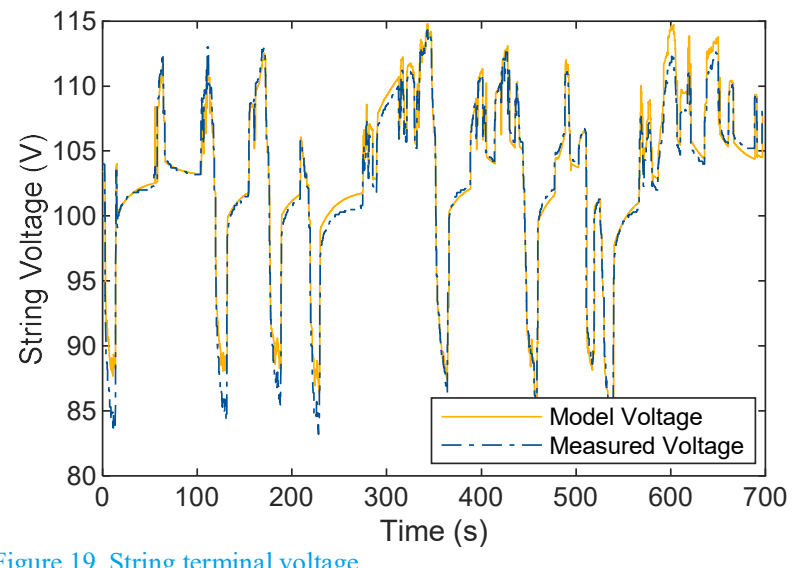

Figure 19. String terminal voltage

When the strings are placed in parallel with each other in the model, the varying resistances within the strings cause a slightly uneven current distribution; this is shown in Figure 20. Figure 21 depicts a zoomed in portion of the currents, showing that the difference in current between strings is only around $0.01 \mathrm{C}$. This may seem an insignificant amount, but with high C-rates and operation over an extended period, this could cause a noticeable imbalance in the SOC between strings.

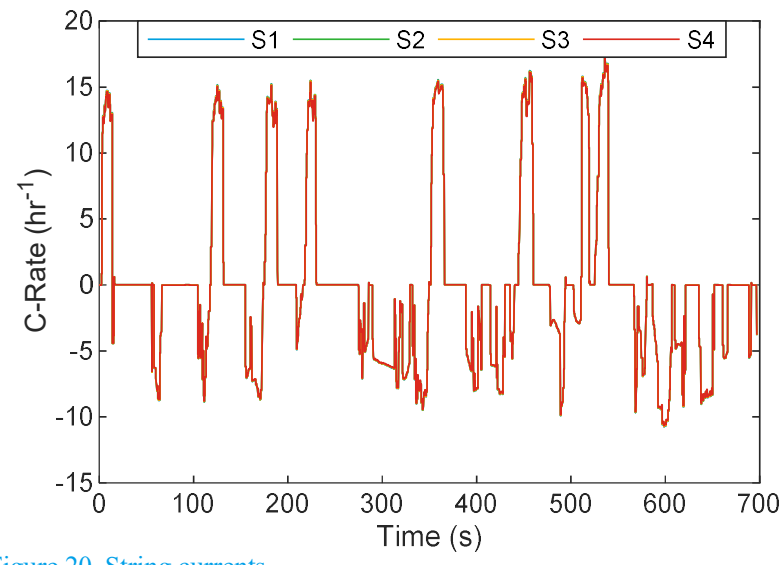

Figure 20. String currents

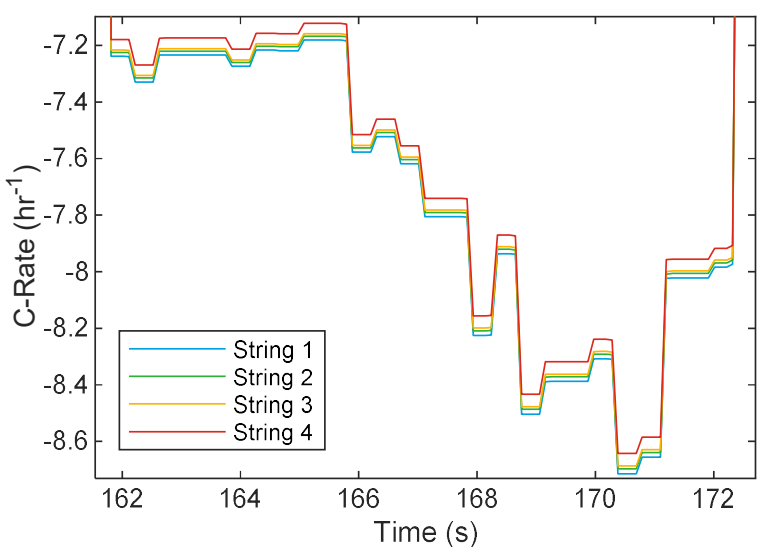

Figure 21. String currents close-up

The model errors are summarized in Table 1, where the error between the model and measured data are quantified using the mean error $(\mu)$, standard deviation $(\sigma)$, mean absolute error (EMAE), root mean square error ( $E_{R M S}$ ), and the absolute difference between $E_{M A E}$ and $E_{R M S}$, $(\Delta \mathrm{E})$.

Table 1. Model error summary

\begin{tabular}{|l|l|l|l|}
\hline Error & SOC (\%) & $\begin{array}{l}\text { Cell terminal } \\
\text { voltage (V) }\end{array}$ & $\begin{array}{l}\text { String terminal } \\
\text { voltage (V) }\end{array}$ \\
\hline $\boldsymbol{\mu}$ & 0.1217 & -0.0092 & -0.3809 \\
\hline $\boldsymbol{\sigma}$ & 0.2094 & 0.0298 & 1.2471 \\
\hline $\mathbf{E}_{\mathrm{MAE}}$ & 0.1913 & 0.0198 & 0.8282 \\
\hline $\mathbf{E}_{\mathbf{R M S}}$ & 0.0587 & $9.7474 \times 10^{-4}$ & 1.7003 \\
\hline$\Delta \mathbf{E}$ & 0.1326 & 0.0298 & 0.8720 \\
\hline
\end{tabular}

These results show that the overall pack model has sufficient accuracy, whilst simultaneously showing the potential for weaknesses in cells through variation in capacity and internal resistance. Therefore, an electrical battery pack model that has accurate terminal voltage and SOC prediction alone is not sufficient for an HEV battery pack; the model should also include cell-to-cell variations to identify potentially weaker cells where high C-rates are likely.

\section{Conclusions}

An electrical model has been created at cell, string, and pack level that models SOC and terminal voltage, but also considers cell-to-cell variations due to manufacturing defects. It was shown that a variation in capacity amongst cells in a string does influence their SOC; however, a variation in internal series resistance does not have a significant effect on their terminal voltage. The variation in internal series resistance also affects the current distribution between strings, which can explain why certain cells in a pack can cause string failure when other cells in the pack appear to be in good health. It was concluded that a "large cell" pack model is not sufficient to model the full battery pack, as this will not consider the variations between cells and therefore which cells may potentially degrade at different rates. 


\section{Future Work}

The next stage of this project will be the creation of thermal cell and pack sub-models, which will model the heat generation by individual cells, the heat transfer between adjacent cells, and finally the heat transfer to the cooling system. An ageing sub-model will also be created that will model the capacity fade of individual cells due to cycling and other ageing factors. There will then be an investigation into whether cell location within the pack has any correlation with its capacity fade, and this will then be implemented into the ageing submodel.

\section{References}

[1] Department for Business Energy \& Industrial Strategy, "2016 UK Greenhouse Gas Emissions, Final Figures Statistical Release: National Statistics," no. February, 2018.

[2] L. Zheng, L. Zhang, J. Zhu, G. Wang, and J. Jiang, "Co-estimation of state-of-charge, capacity and resistance for lithium-ion batteries based on a high-fidelity electrochemical model," Appl. Energy, vol. 180, pp. 424-434, 2016

[3] A. Jokar, B. Rajabloo, M. Désilets, and M. Lacroix, "Review of simplified Pseudo-two-Dimensional models of lithium-ion batteries," J. Power Sources, vol. 327, pp. 44-55, 2016.

[4] S. Santhanagopalan, Q. Guo, P. Ramadass, and R. E. White, "Review of models for predicting the cycling performance of lithium ion batteries," J. Power Sources, vol. 156, no. 2, pp. 620628, 2006.

[5] S. Pramanik and S. Anwar, "Electrochemical model based charge optimization for lithium-ion batteries," J. Power Sources, vol. 313, pp. 164-177, 2016.

[6] O. Nelles, "Neural Networks," in Nonlinear System Identifcation, Berlin: Springer, 2001, p. 785.

[7] D. Andre, A. Nuhic, T. Soczka-Guth, and D. U. Sauer, "Comparative study of a structured neural network and an extended Kalman filter for state of health determination of lithium-ion batteries in hybrid electric vehicles," Eng. Appl. Artif. Intell., vol. 26, no. 3, pp. 951-961, 2013.

[8] X. Dang, L. Yan, K. Xu, X. Wu, H. Jiang, and H. Sun, "Open-Circuit Voltage-Based State of Charge Estimation of Lithium-ion Battery Using Dual Neural Network Fusion Battery Model," Electrochim. Acta, vol. 188, pp. 356-366, 2016.

[9] A. Nikolian, J. De Hoog, K. Fleurbay, J. Timmermans, P. Van De Bossche, and J. Van Mierlo, "Classification of Electric modelling and Characterization methods of Lithium-ion Batteries for Vehicle Applications," Eur. Electr. Veh. Congr., no. February 2016, pp. 115,2014

[10] A. Nikolian et al., "Complete cell-level lithium-ion electrical ECM model for different chemistries (NMC, LFP, LTO) and temperatures $\left(-5^{\circ} \mathrm{C}\right.$ to $\left.45^{\circ} \mathrm{C}\right)$ - Optimized modelling techniques," Int. J. Electr. Power Energy Syst., vol. 98, no. December 2017, pp. 133-146, 2018

[11] R. Jackey, M. Saginaw, P. Sanghvi, J. Gazzarri, T. Huria, and M. Ceraolo, "Battery Model Parameter Estimation Using a Layered Technique: An Example Using a Lithium Iron Phosphate Cell," MathWorks, pp. 1-14, 2013.

[12] S. Nejad, D. T. Gladwin, and D. A. Stone, "A systematic review of lumped-parameter equivalent circuit models for real-time estimation of lithium-ion battery states," J. Power Sources, vol. 316 , pp. 183-196, 2016.

[13] X. Hu, S. Li, and H. Peng, "A comparative study of equivalent circuit models for Li-ion batteries," J. Power Sources, vol. 198, pp. 359-367, 2012.

[14] A. Van Der Ven, J. Bhattacharya, and A. A. Belak, "Understanding Li diffusion in Li-intercalation compounds," Acc. Chem. Res., vol. 46, no. 5, pp. 1216-1225, 2013.

[15] M. A. Roscher, O. Bohlen, and J. Vetter, "OCV Hysteresis in Li-Ion Batteries including Two-Phase Transition Materials," Int. J. Electrochem., vol. 2011, pp. 1-6, 2011.

[16] H. Rahimi Eichi and M. Y. Chow, "Modeling and analysis of battery hysteresis effects," 2012 IEEE Energy Convers. Congr. Expo. ECCE 2012,pp. 4479-4486, 2012

[17] M. A. Roscher and D. U. Sauer, "Dynamic electric behavior and open-circuit-voltage modeling of LiFePO 4-based lithium ion secondary batteries," J. Power Sources, vol. 196, no. 1, pp. 331336,2011

[18] G. L. Plett, "Extended Kalman filtering for battery managemen systems of LiPB-based HEV battery packs - Part 2. Modeling and identification," J. Power Sources, vol. 134, no. 2, pp. 262-276, 2004

[19] L. Zhong, C. Zhang, Y. He, and Z. Chen, "A method for the estimation of the battery pack state of charge based on in-pack cells uniformity analysis," Appl. Energy, vol. 113, pp. 558-564, 2014.

[20] R. Gogoana, M. B. Pinson, M. Z. Bazant, and S. E. Sarma, "Internal resistance matching for parallel-connected lithium-ion cells and impacts on battery pack cycle life," J. Power Sources, vol. 252, pp 8-13, 2014.

[21] X. Gong, R. Xiong, and C. C. Mi, "Study of the Characteristics of Battery Packs in Electric Vehicles with Parallel-Connected LithiumIon Battery Cells," Conf. Proc. - IEEE Appl. Power Electron. Conf. Expo. - APEC, pp. 3218-3224, 2014.

[22] T. Bruen and J. Marco, "Modelling and experimental evaluation of parallel connected lithium ion cells for an electric vehicle battery system," J. Power Sources, vol. 310, pp. 91-101, 2016.

[23] C. Sen and N. C. Kar, "Battery pack modeling for the analysis of battery management system of a hybrid electric vehicle," 2009 IEEE Veh. Power Propuls. Conf., pp. 207-212, 2009.

[24] B. J. Yurkovich and Y. Guezennec, "Lithium Ion Dynamic Battery Pack Model and Simulation for Automotive Applications," ASME Dyn. Syst. Control Conf., pp. 1-8, 2009.

[25] B. Kenney, K. Darcovich, D. D. MacNeil, and I. J. Davidson, "Modelling the impact of variations in electrode manufacturing on lithium-ion battery modules," J. Power Sources, vol. 213, pp. 391$401,2012$.

[26] M. Dubarry, N. Vuillaume, and B. Y. Liaw, "From single cell mode to battery pack simulation for Li-ion batteries," J. Power Sources, vol. 186, no. 2, pp. 500-507, 2009.

[27] A. Cordoba-Arenas, S. Onori, and G. Rizzoni, “A control-oriented lithium-ion battery pack model for plug-in hybrid electric vehicle cycle-life studies and system design with consideration of health management," J. Power Sources, vol. 279, pp. 791-808, 2015.

\section{Nomenclature}

C

$\mathrm{C}_{1}$

EMAe

ERMS

h

ic1

icell

iR1

$\mathbf{k}$

M
Capacity (C)

RC capacitance $(\mathrm{F})$

Model mean absolute error

Model root mean square error

Hysteresis voltage (V)

Pack current (A)

Pack current

$\mathrm{RC}$ capacitor current (A)

Cell current (A)

String current (A)

$\mathrm{RC}$ resistor current (A)

Sample (-)

Maximum hysteresis voltage (V) 
Number of cells in series (-)

OCV

Open-circuit voltage (V)

$\mathbf{R}_{0}$

Series resistance $(\Omega)$

$\mathbf{R}_{1}$

$\mathrm{RC}$ resistance $(\Omega)$

$\mathbf{R}_{\mathbf{i}}$

String resistance $(\Omega)$

$\mathbf{R}_{\mathbf{i j}}$

The resistance of cell $\mathrm{i}$ in string $\mathrm{j}(\Omega)$

$\mathbf{R}_{\mathbf{T}}$

Overall pack resistance $(\Omega)$

SOC

$\mathbf{t}$

VC1

$\dot{\mathbf{v}}_{\mathrm{C} 1}$

Vcell

$\mathbf{V}_{\text {pack }}$

$\gamma$

$\Delta \mathbf{E}$

$\Delta \mathbf{t}$

$\eta$

$\boldsymbol{\mu}$

$\sigma$

State of charge $(\%)$

Time (s)

$\mathrm{RC}$ capacitor voltage $(\mathrm{V})$

The rate of change of RC capacitor voltage $(\mathrm{V} / \mathrm{s})$

Cell terminal voltage $(\mathrm{V})$

Pack voltage

Hysteresis factor (-)

Difference in errors

Time step (s)

Coulombic efficiency (\%)

Model error mean

Model error standard deviation

\section{Contact Information}

Ryan Rolt

Work phone: +44 2890974949

Email: rrolt01@qub.ac.uk

\section{Acknowledgements}

This project was financially supported by the Department for the Economy in Northern Ireland (DfE), Wrightbus, and Queen's University Belfast.

\section{Acronyms and Abbreviations}

ANN

CAN
GHG

HEV

$\mathrm{LFP}_{\mathrm{LiFePO}}$

Li-ion

$\mathrm{LiC}_{6}$

$\mathrm{LTO}_{/ \mathrm{Li}_{4}} \mathrm{Ti}_{5} \mathrm{O}_{12}$

OCV

P2D

RC

RMSE

SOC

SPM

TTW

UK

$1 D$
Electrical equivalent circuit model

Electric Vehicle

First Group Millbrook Fuel Economy Test Version 5.0

Greenhouse gas

Hybrid electric vehicle

Lithium iron phosphate

Lithium-ion

Lithiated graphite

Lithium titanate

Open-circuit voltage

Pseudo-two-dimensional

Resistor-capacitor

Root mean square error

State of charge

Single particle model

Tank-to-wheel

United Kingdom

One-dimensional 